\title{
Article \\ Biomechanical Evaluation of Cortical Bone Trajectory Fixation with Traditional Pedicle Screw in the Lumbar Spine: A Finite Element Study
}

\author{
Kuo-Chih Su ${ }^{1,2,3}$ (D), Kun-Hui Chen ${ }^{4,5,6}$, Chien-Chou Pan ${ }^{4,7}$ and Cheng-Hung Lee ${ }^{4,5,8, *}$ \\ 1 Department of Medical Research, Taichung Veterans General Hospital, Taichung 407, Taiwan; \\ kcsu@vghtc.gov.tw \\ 2 Department of Biomedical Engineering, Hungkuang University, Taichung 433, Taiwan \\ 3 Department of Chemical and Materials Engineering, Tunghai University, Taichung 407, Taiwan \\ 4 Department of Orthopedics, Taichung Veterans General Hospital, Taichung 407, Taiwan; \\ orthochen@gmail.com (K.-H.C.); adonisvgh@gmail.com (C.-C.P.) \\ 5 College of Medicine, National Chung Hsing University, Taichung 402, Taiwan \\ 6 Department of Computer Science and Information Engineering, Providence University, Taichung 433, Taiwan \\ 7 Department of Rehabilitation Science, Jenteh Junior College of Medicine, Nursing and Management, \\ Miaoli 356, Taiwan \\ 8 Department of Food Science and Technology, Hungkuang University, Taichung 433, Taiwan \\ * Correspondence: 298f@vghtc.gov.tw; Tel.: +886-4-2359-2525 (ext. 5101)
}

Citation: Su, K.-C.; Chen, K.-H.; Pan, C.-C.; Lee, C.-H. Biomechanical Evaluation of Cortical Bone Trajectory Fixation with Traditional Pedicle Screw in the Lumbar Spine: A Finite Element Study. Appl. Sci. 2021, 11, 10583. https://doi.org/10.3390/ app112210583

Academic Editor: Claudio Belvedere

Received: 10 October 2021

Accepted: 8 November 2021

Published: 10 November 2021

Publisher's Note: MDPI stays neutral with regard to jurisdictional claims in published maps and institutional affiliations.

Copyright: (C) 2021 by the authors. Licensee MDPI, Basel, Switzerland. This article is an open access article distributed under the terms and conditions of the Creative Commons Attribution (CC BY) license (https:/ / creativecommons.org/licenses/by/ $4.0 /)$.

\begin{abstract}
Cortical bone trajectory (CBT) is increasingly used in spinal surgery. Although there are many biomechanical studies, the biomechanical effect of CBT in combination with traditional pedicle screws is not detailed. Therefore, the purpose of this study was to investigate the effects of the traditional pedicle screw and CBT screw implantation on the lumbar spine using finite element methods. Based on the combination of the traditional pedicle screw and the CBT system implanted into the lumbar spine, four finite element spinal lumbar models were established. The models were given four different load conditions (flexion, extension, lateral bending, and axial rotation), and the deformation and stress distribution on the finite element model were observed. The results show that there was no significant difference in the structural stability of the lumbar spine model between the traditional pedicle screw system and the CBT system. In addition, CBT may reduce stress on the endplate. Different movements performed by the model may have significant biomechanical effects on the spine and screw system. Clinical spinal surgeons may also consider using the CBT system in revision spinal surgery, which may contribute to smaller wounds.
\end{abstract}

Keywords: cortical bone trajectory; traditional pedicle screw; biomechanics; finite element analysis

\section{Introduction}

The traditional pedicle screw fixation system has been widely used in the treatment of lumbar diseases such as disc herniation and disc stenosis. The traditional pedicle screw remains the most commonly used for spinal surgery. However, for patients with osteoporosis, due to the lack of fixation force of pedicle screws, complications such as screw loosening, displacement, and prolapse easily occur [1]. In addition, interbody fusion may accelerate degeneration of adjacent segments of the spine, resulting in adjacent segment disease (ASD) [2]. As a result, the rate of revision surgery within 5 years is as high as $20 \%$ in patients undergoing lumbar fusion $[3,4]$. When performing ASD revision surgery, the surgeon often needs to remove the original vertebra screw fixation, which increases the exposure of the patient's surgical wound. This not only increases surgical time, blood loss, and surgical trauma but also increases the risk of postoperative infection [4]. Therefore, revision surgery is often more difficult than primary surgery, and there are many problems such as intraoperative bleeding and surgical complications. In addition, whether the 
revision surgery uses the same approach as the previous surgery and whether retaining the original pedicle screw are common problems encountered by clinical spine surgeons [5].

Cortical bone trajectory (CBT) is an improvement, and development of traditional pedicle screw fixation in patients with osteoporosis can significantly reduce intraoperative blood loss [6,7]. CBT screws are implanted closer to the midline spinous process than traditional pedicle screws and have less soft tissue dissection. Additionally, CBT screws are implanted in an inward downward upward direction, which is less likely to invade the adjacent intervertebral joints. In addition, the screw and cortical bone contact area are large, so it can increase the screw torque or pull force, avoiding a loose screw [8]. The advent of CBT internal screw fixation provides a new idea for revision surgery for ASD patients. A CBT screw can be used to achieve revision by combining it with a traditional pedicle screw. There are a number of spinal surgeons who perform this type of surgery, and they all have good results [9-12]. Although CBT screws and traditional pedicle screws have reached similar revision surgery rates and fusion rates [13], CBT screws and traditional pedicle screws are implanted in different positions in the vertebral body of the spine. Thus, the combined structure of using a CBT screw and a traditional pedicle screw is more complicated. Therefore, more mechanical analysis is needed to evaluate the stability.

Finite element analysis has been used to evaluate the mechanical outcome of CBT screw implantation [14]. One researcher evaluated the size of different CBT screw implants. The results showed that the ideal screw size for CBT is greater than $5.5 \mathrm{~mm}$ in diameter and $35 \mathrm{~mm}$ in length [15]. Other researchers also assessed the difference between CBT screw implantation and traditional pedicle screws using a finite element method [16-18]. However, the results of each study were inconsistent, so the difference between CBT screw implantation and traditional pedicle screws was still worth discussing. A finite element analysis model of a CBT screw combined with a traditional pedicle screw was also established [19]. The biomechanical evaluation was compared with the CBT screw system, traditional pedicle screw system, and universal spine system. The results showed that CBT screws did not exhibit better mechanical properties than traditional pedicle screw systems and universal spine systems. This previous study only established three vertebrae and two discs. Therefore, biomechanical evaluation of the vertebral body near the intervertebral disc was not performed. It is also important to observe the biomechanical effects of adjacent segments after the vertebral screw system is implanted in the vertebral body. Therefore, the establishment of a multi-segment finite element analysis spinal model could understand the situation of adjacent segments after the implantation of the vertebral screw system and provide a clearer biomechanical evaluation.

According to previous research, CBT screws are increasingly used in spinal surgery. Although there were many biomechanical studies, there was no detailed biomechanical assessment of the combination of CBT screw and traditional pedicle screw. Therefore, the objective of this study was to investigate the effects of the traditional pedicle screw and CBT screw implant on the lumbar spine using the finite element method. The results of this study can provide a biomechanical basis for clinical chiropractors to select spinal implants and reduce the rate of surgical failure.

\section{Materials and Methods}

\subsection{Simulation of Lumbar Geometry Model}

In this study, CT images were used to establish a computer lumbar spine analysis model. The source of CT images is obtained from an artificial lumbar vertebrae model (SKU:1352, Sawbones Inc., Vashon Island, WA, USA) as well as the CT scan. Using the medical image reconstruction application software Mimics (Mimics Medical 20.0, Materialise, Leuven, Belgium), a grayscale value of the CT image was used to select the bone portion of the spine model in the CT image and for the segmentation of the computer spine model. After selecting the lumbar model using the Mimics medical imaging software, the model was imported into the three-dimensional computer-aided design (CAD) software (Solidworks 2016, Dassault Systemes SolidWorks Corp., Waltham, 
MA, USA) for the drawing of other important parts of the computer lumbar spine model (Figure 1). This study divides the spine model into 19 parts, consisting of the cortical bone, cancellous bone, nucleus pulposus of the intervertebral disc, and the three parts from the center to the outer endplate, posterior elements, seven-layer annulus ground substance, and seven-layer annulus fibrosis. The intervertebral disc is composed of annulus and nucleus pulposus, of which annulus is formed by annulus ground substance and annulus fibrosis. Each ring of annulus fibrosis is surrounded by fibers tilted at an angle of $30^{\circ}$ or $150^{\circ}$ with the horizontal line. A three-dimensional CAD software Solidworks was also used to establish the different parts of the ligament, such as the anterior longitudinal ligament posterior longitudinal ligament, Ligamentum flavum, interspinous ligament, supraspinous ligament, transverse ligament and facet capsulary ligament (Figure 2).

\section{Artificial lumbar spine model}

CT image segmentation

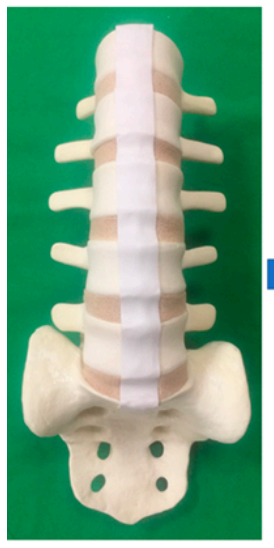

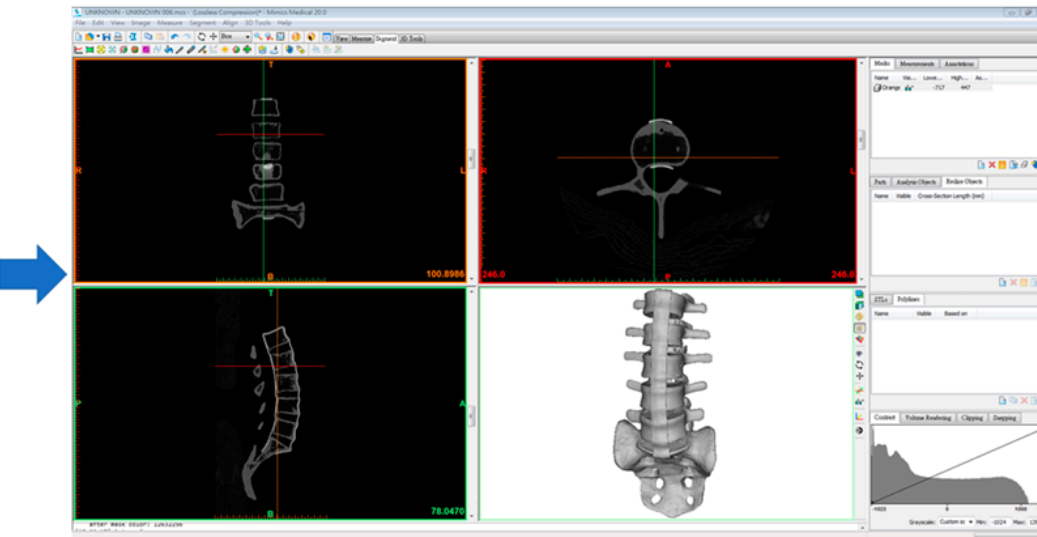

Computer model

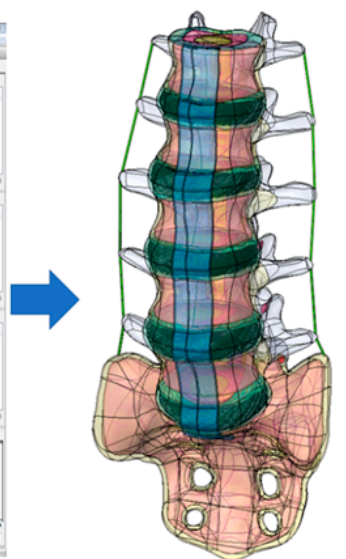

Figure 1. Creating a computer lumbar spine model using an artificial spine CT image for segmentation by the Mimics medical imaging software.

(a)

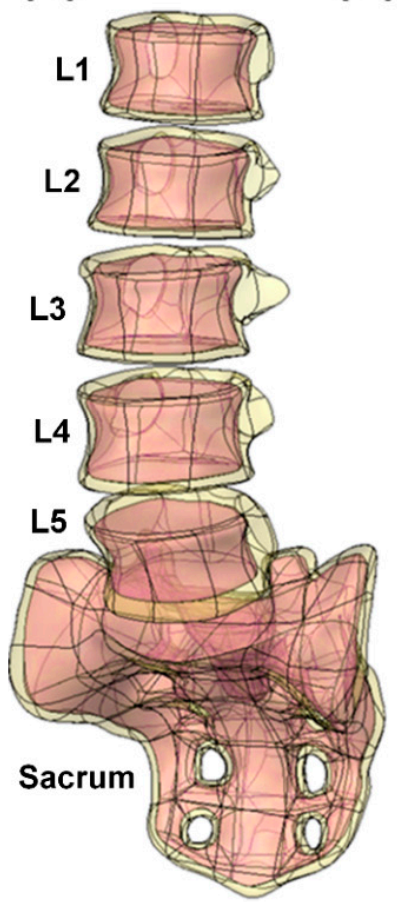

(c)

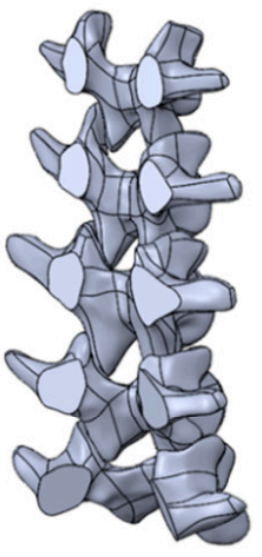

(d)

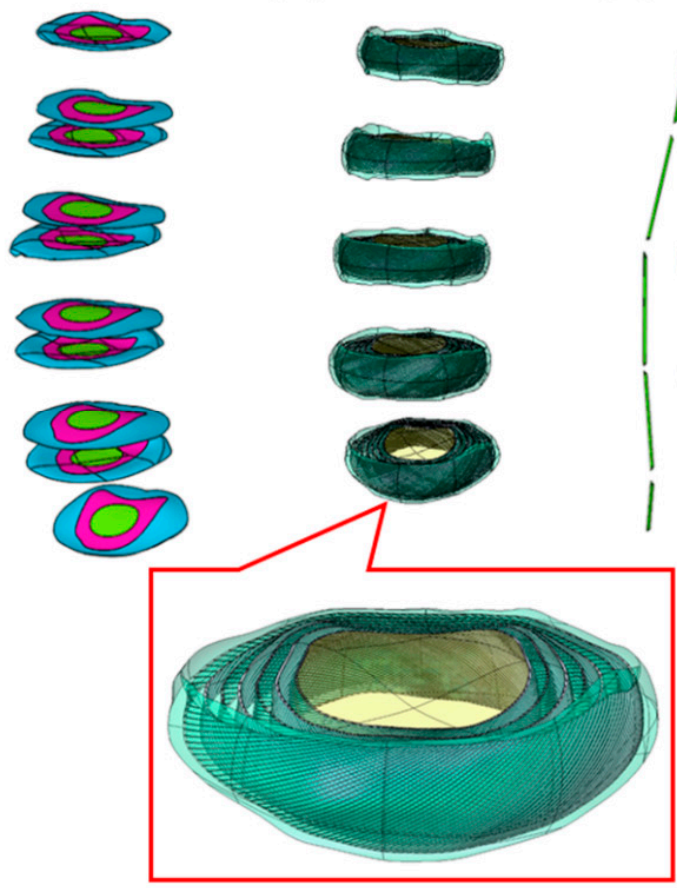

(e)

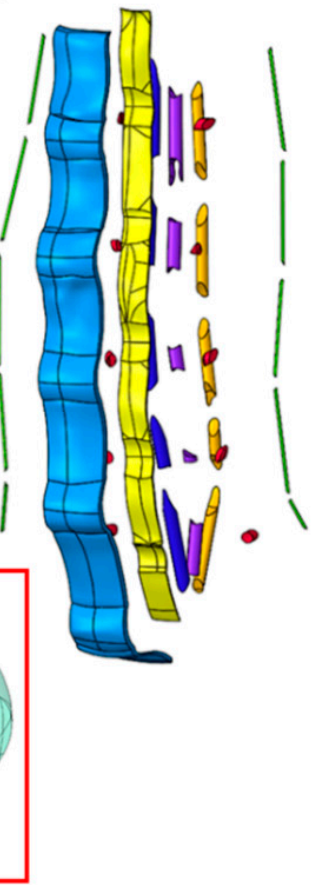

Figure 2. Parts of the lumbar spine computer model. (a) Cortical bone and cancellous bone. (b) Posterior elements. (c) Endplate. (d) Intervertebral disc (annulus ground substance and annulus fibrosis). (e) Ligaments. 


\subsection{Traditional Pedicle Screw System and Cortical Bone Trajectory System}

Computer models of the cage for transforaminal lumbar interbody fusion, a traditional pedicle screw system, and a CBT system were established. The traditional pedicle screw system (5.5 $\mathrm{mm}$ in diameter and $45 \mathrm{~mm}$ in length) and cortical bone trajectory system (5.5 $\mathrm{mm}$ in diameter and $35 \mathrm{~mm}$ in length) are composed of the screw, screw tulip, and rod. A cage was placed between L3 and L4 in the lumbar model. The cage is in contact with the endplate; some intervertebral disc structures were removed, mainly to simulate the situation of clinical cage implantation (Figure 3). This study was divided into four groups based on CBT and traditional pedicle screw implantation in the lumbar vertebrae L3 and L4 (the CBT screws were implanted in contact with the cortical bone of the vertebral body, and the traditional pedicle screws were controlled and implanted into the cancellous bone of the vertebral body) (Figure 4). In the first group, the lumbar vertebrae L3 and L4 are fixed with traditional pedicle screws. The second group was treated with CBT between L3 and L4. In the third group, L3 was fixed with a traditional pedicle screw and L4 was fixed with CBT. In the fourth group, L3 was fixed with CBT, and L4 was fixed with a traditional pedicle screw. Then, the four computer models were imported into the finite element analysis software ANSYS Workbench (ANSYS Workbench 18.0, ANSYS, Inc., Canonsburg, PA, USA) for finite element analysis.

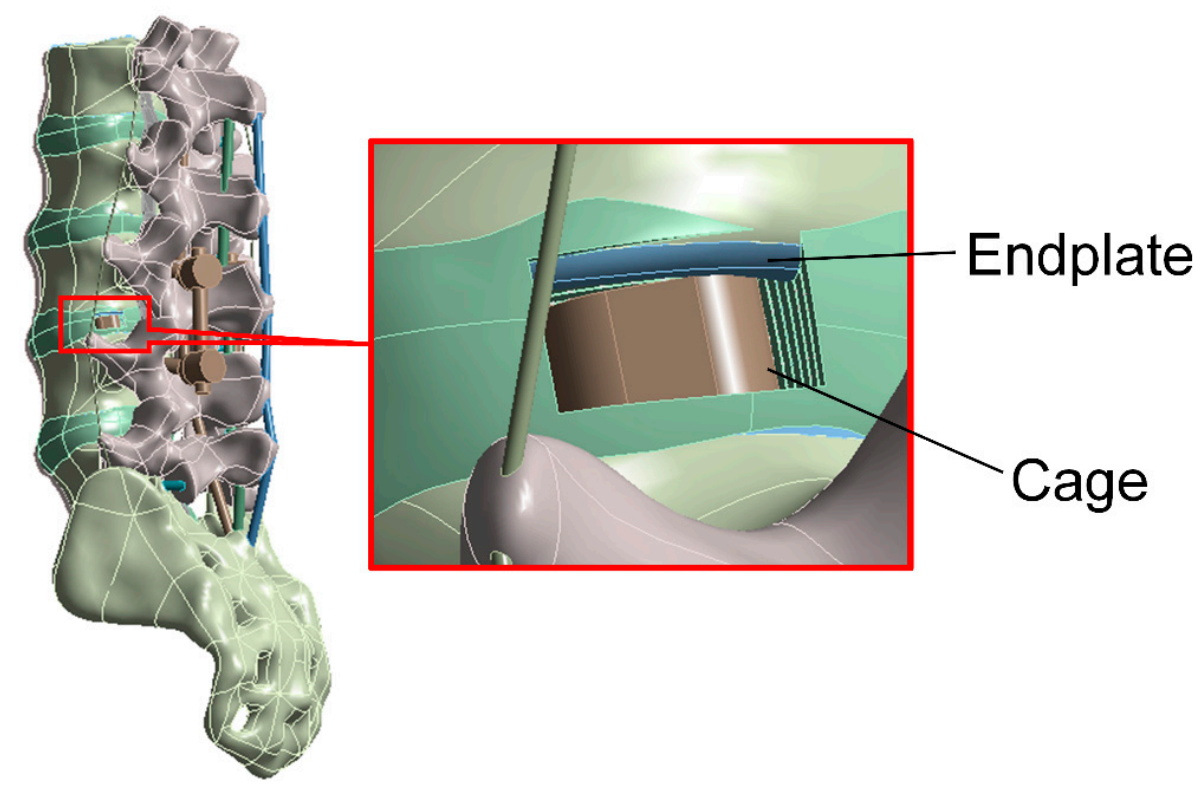

Figure 3. The cage is in contact with the endplate; some intervertebral disc structures were removed. 


\section{Group 1 \\ Group 2}

Traditional pedicle screw

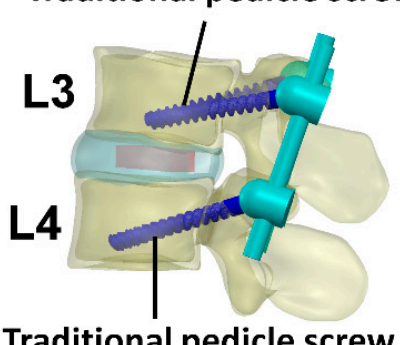

Traditional pedicle screw

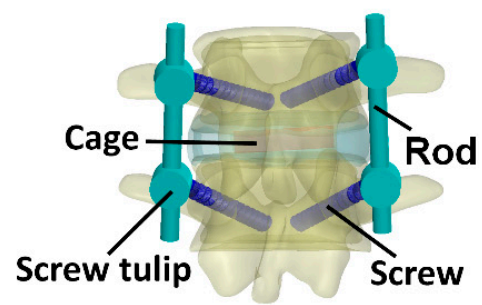

Cortical bone trajectory

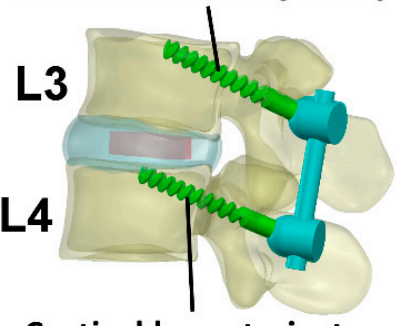

Cortical bone trajectory

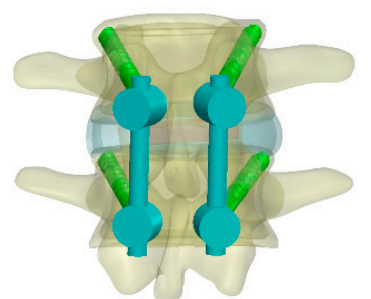

Group 3

Traditional pedicle screw

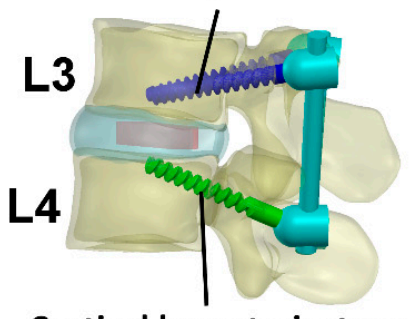

Cortical bone trajectory

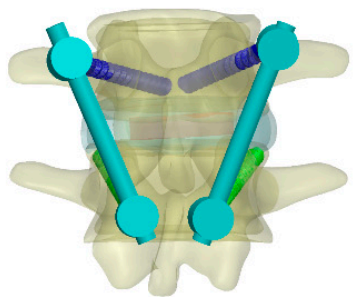

Group 4

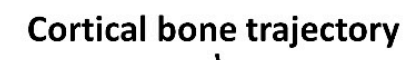

Figure 4. According to the CBT and the traditional pedicle screw placement into the lumbar spine, L3 and L4 are divided into four groups.

\subsection{Loading Conditions and Boundary Conditions}

As for the set of boundary and load conditions, four movements, including flexion, extension, lateral bending, and axial rotation, were carried out for the lumbar spine based on previous research data $[20,21]$. Therefore, the boundary conditions are mainly fixed at the lower edge of both sides of the sacrum model (the displacement at the $x$-axis, $y$-axis, and $z$-axis are set at 0 ). In terms of load conditions, the main follower load is given to the spine of $400 \mathrm{~N}$. In addition, for flexion, extension, lateral bending, and axial rotation movements, $10 \mathrm{Nm}$ load conditions were set on the upper side of L1 of the lumbar spine [22,23] (Figure 5).

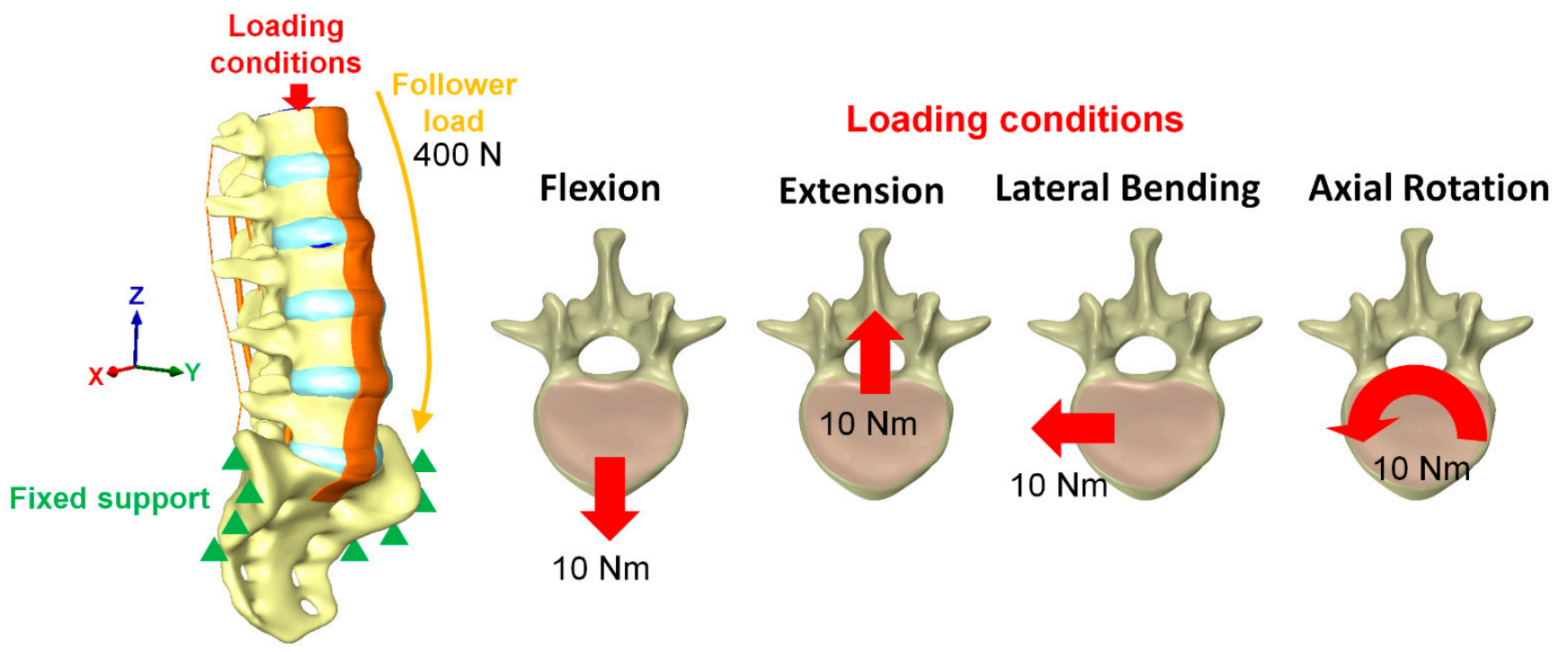

Figure 5. Loading conditions and boundary conditions.

\subsection{Material Properties of the Model}

The material properties of the lumbar spine model established in this study are derived from previous studies [24-30]. A cage, traditional pedicle screw system, and CBT 
system were used to simulate titanium alloy. Assume that all materials are homogeneous, isotropic, and linearly elastic. Therefore, two independent parameters (Young's modulus and Poisson's ratio) were used to represent material properties. Table 1 shows the properties of the materials used in this finite element study. In addition, the mesh elements used in the computer model for finite element analysis in this study are tetrahedral mesh (Figure 6). In addition to experimental verification, the computer model used in this study also needs to pass the mesh convergence test. The convergence test used in this study is mainly controlled by mesh size as the basis of convergence. The mesh sizes of the convergence test control were 5, 4, 3, 2, and $1 \mathrm{~mm}$, respectively. After the convergence test, the model reaches the $5 \%$ stop criterion of the convergence test [31]. Therefore, the finite element mesh model adopted in this study is reasonable (the mesh size adopted in this study is $2 \mathrm{~mm}$ ).

Table 1. Material properties in this study [24-30].

\begin{tabular}{ccc}
\hline Materials & Young's Modulus (MPa) & Poisson's Ratio \\
\hline Cortical bone & 12,000 & 0.3 \\
Cancellous bone & 100 & 0.3 \\
Endplate-central & 2000 & 0.3 \\
Endplate-intermediate & 6000 & 0.3 \\
Endplate-outer & 12,000 & 0.3 \\
Posterior elements & 3500 & 0.25 \\
Nucleus pulposus & 1 & 0.499 \\
Annulus fibrosis 3-4 & 550 & 0.3 \\
Annulus fibrosis 5-6 & 485 & 0.3 \\
Annulus fibrosis 1-2 (Outermost Layers) & 420 & 0.3 \\
Annulus fibrosis 7 (Innermost Layer) & 360 & 0.3 \\
Annulus ground substance & 4.2 & 0.45 \\
Anterior longitudinal ligament & 20 & 0.3 \\
Posterior longitudinal ligament & 20 & 0.3 \\
Ligamentum flavum & 19.5 & 0.3 \\
Interspinous ligament & 11.6 & 0.3 \\
Supraspinous ligament & 15 & 0.3 \\
Intertransverse ligament & 58.7 & 0.3 \\
Facet capsulary ligament & 32.9 & 0.3 \\
Traditional pedicle screw system & 110,000 & 0.3 \\
Cortical bone trajectory system & 110,000 & 0.3 \\
Cage & 110,000 & 0.3 \\
\hline
\end{tabular}

The main observation indicators were total deformation of the lumbar spine, von Mises stress of the lumbar spine, traditional pedicle screw system and CBT system by finite element analysis. Based on these indicators, biomechanical effects of the implantation of the traditional pedicle screw system and CBT system on lumbar vertebra were evaluated. 


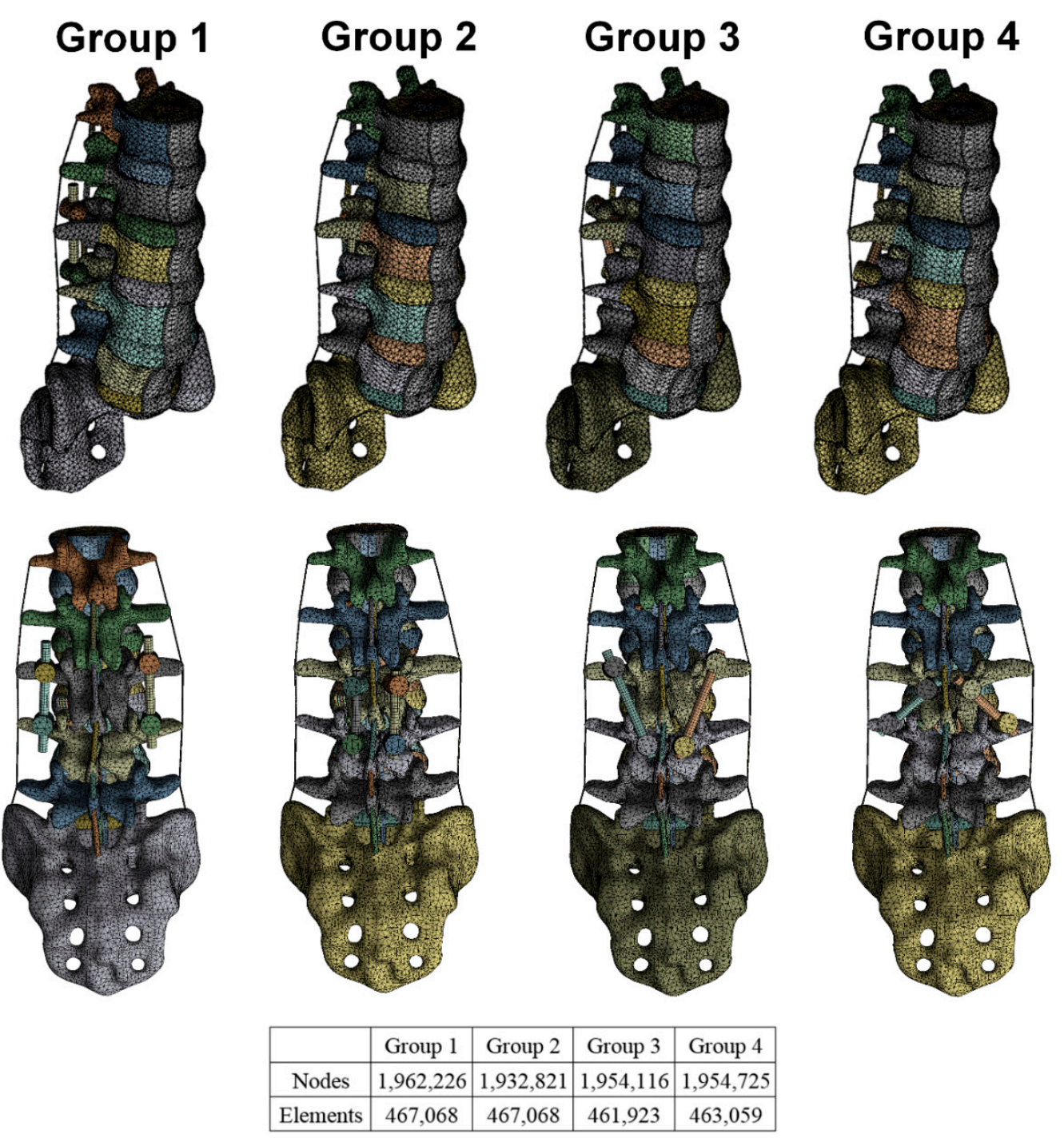

Figure 6. The mesh conditions of the four groups of models in this study and the number of mesh nodes and elements.

\section{Results}

In this study, the stress of the lumbar spine after the implantation of the traditional pedicle screw system and the CBT system was observed by finite element analysis. Figure 7 shows the total deformation of the lumbar spine. The results showed that there was no significant difference in total deformation among all groups. Figure 8 shows the distribution of von Mises stress on the lumbar vertebra under the action of four different movements. There are obvious differences in stress distribution under different actions. There was no significant difference in stress distribution in the lumbar spine with different screw systems. Figure 9 shows peak von Mises stress on the lower endplate of L2 and the upper endplate of L5. Fixed with a traditional pedicle screw system, there was a slightly higher stress value on the endplate of the adjacent lumbar segments. Figure 10 shows peak von Mises stress at L2, L3, L4 and L5 of the lumbar spine. In L2 and L5 of lumbar vertebrae, there was no significant difference in stress distribution of lumbar vertebrae except different peak von Mises stress under the influence of different movements. Peak von Mises stress in L3 of the lumbar spine was observed. The peak von Mises stress in Group 2 and Group 4 was relatively low. The peak von Mises stress in L4 of the lumbar spine was observed, and the peak von Mises stress in Group 1 was relatively lower. 


\section{Total deformation}

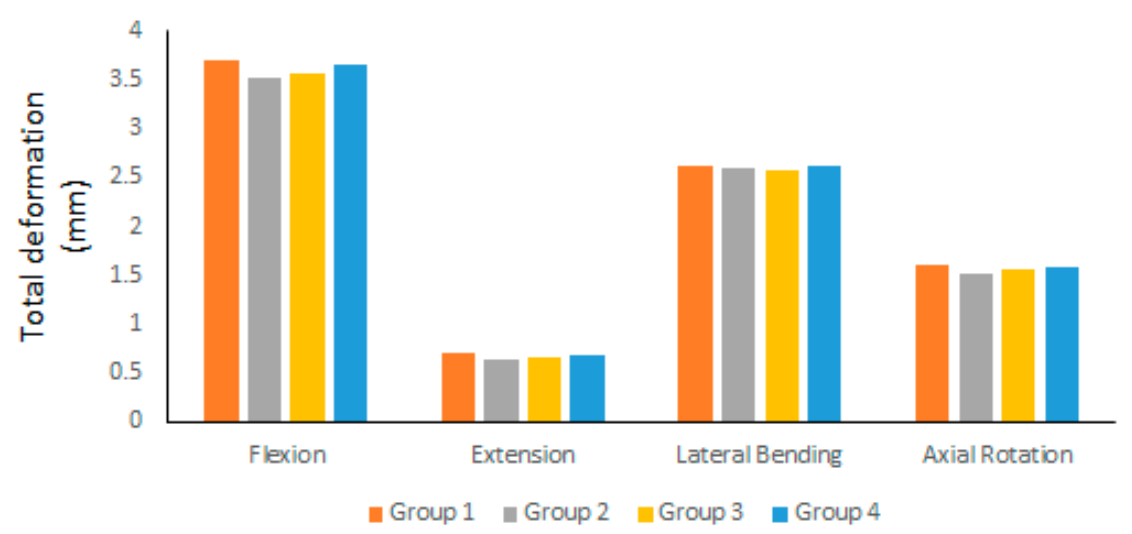

Figure 7. Total deformation of the lumbar spine.
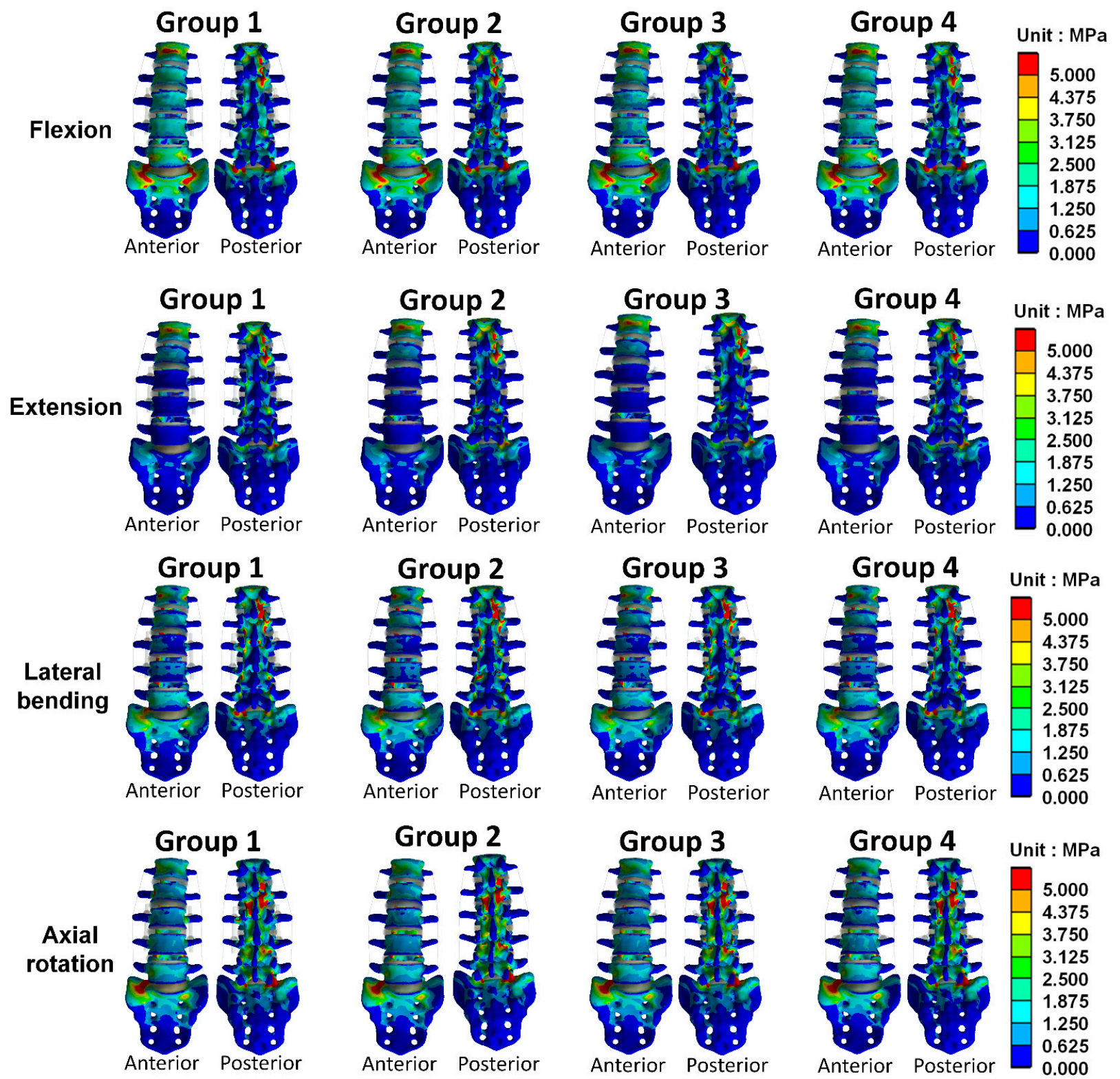

Figure 8. Distribution of von Mises stress on the lumbar spine. 

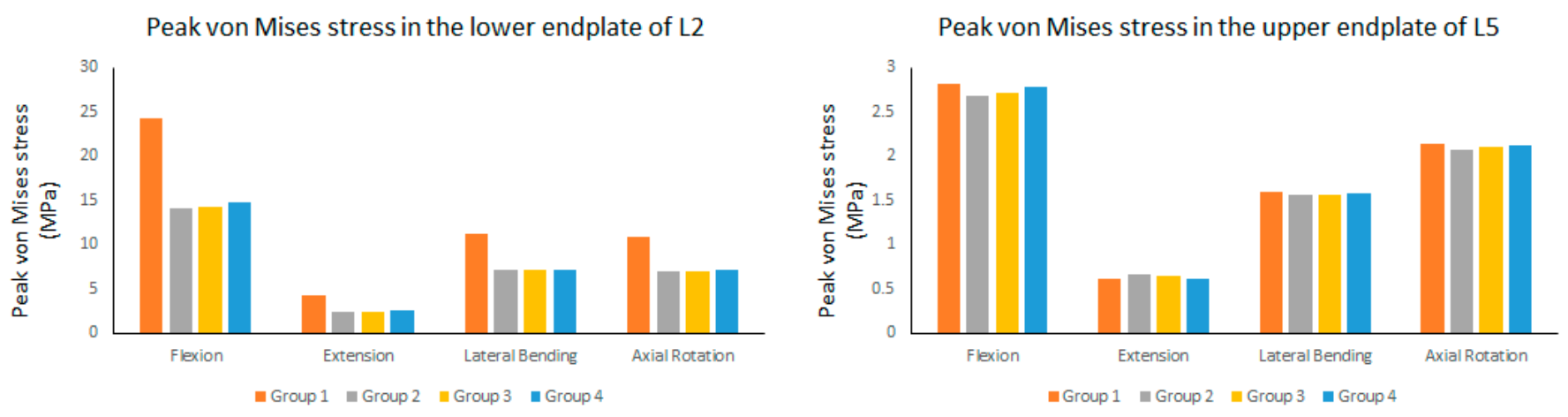

Figure 9. Peak von Mises stress on the lower endplate of L2 and the upper endplate of L5.
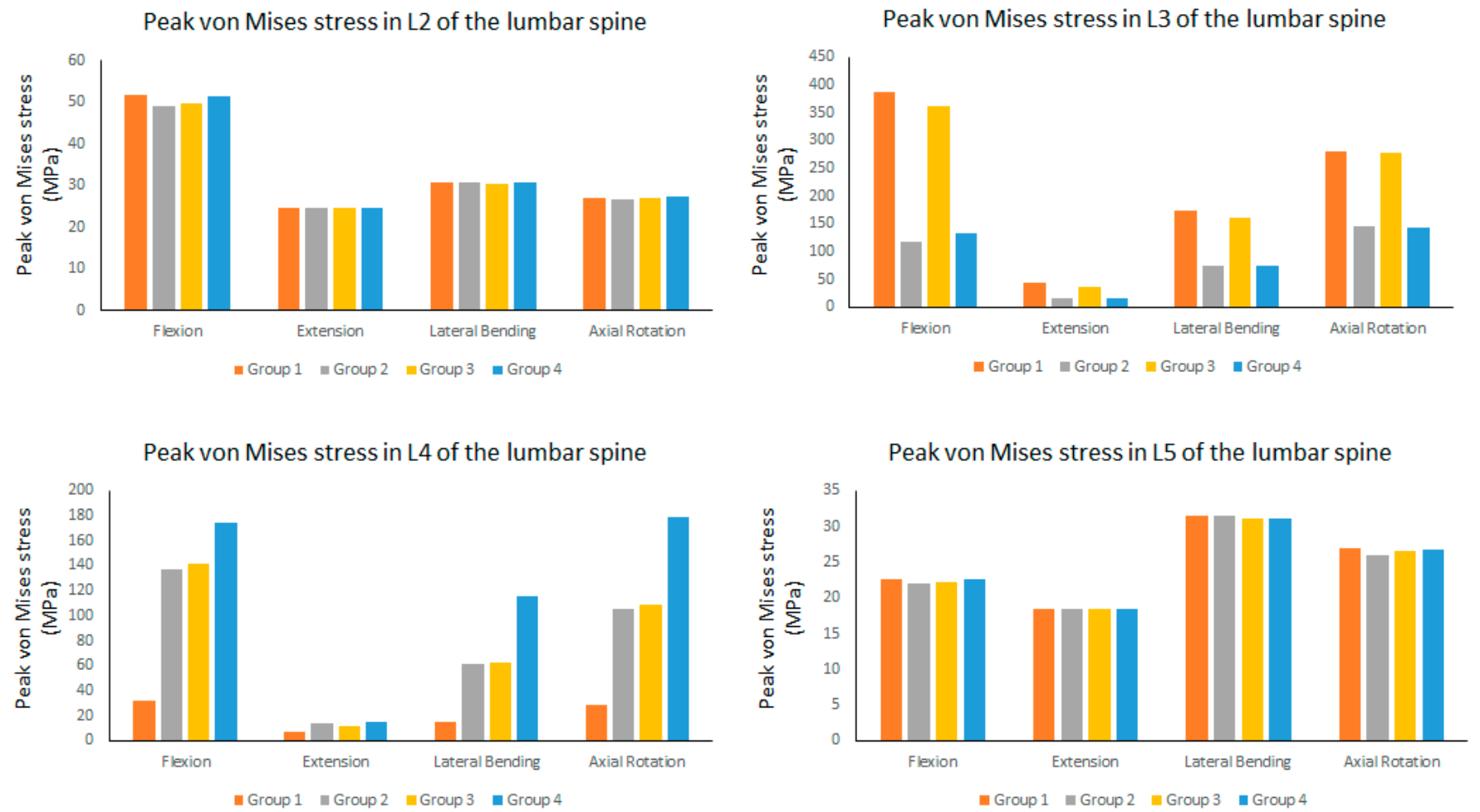

Figure 10. Peak von Mises stress in L2, L3, L4 and L5 of the lumbar spine.

Figure 11 shows the distribution of von Mises stress on the screw system and cage. Screw system high stress mainly occurs near the joint of screw and screw tulip. Cage high stress occurs at the cage edge. Figure 12 showed peak von Mises stress on the cage and screw system. The peak von Mises stress of the cage was significantly different except under the influence of different movements. There was no significant difference in peak von Mises stress in different groups of the cage. Table 2 shows the values of the total deformation on the lumbar spine and the values of peak von Mises stress on the lower endplate of L2, the upper endplate of L5, L2, L3, L4, and L5 of the lumbar spine, cage, screw, rod and screw tulip of the screw system. 

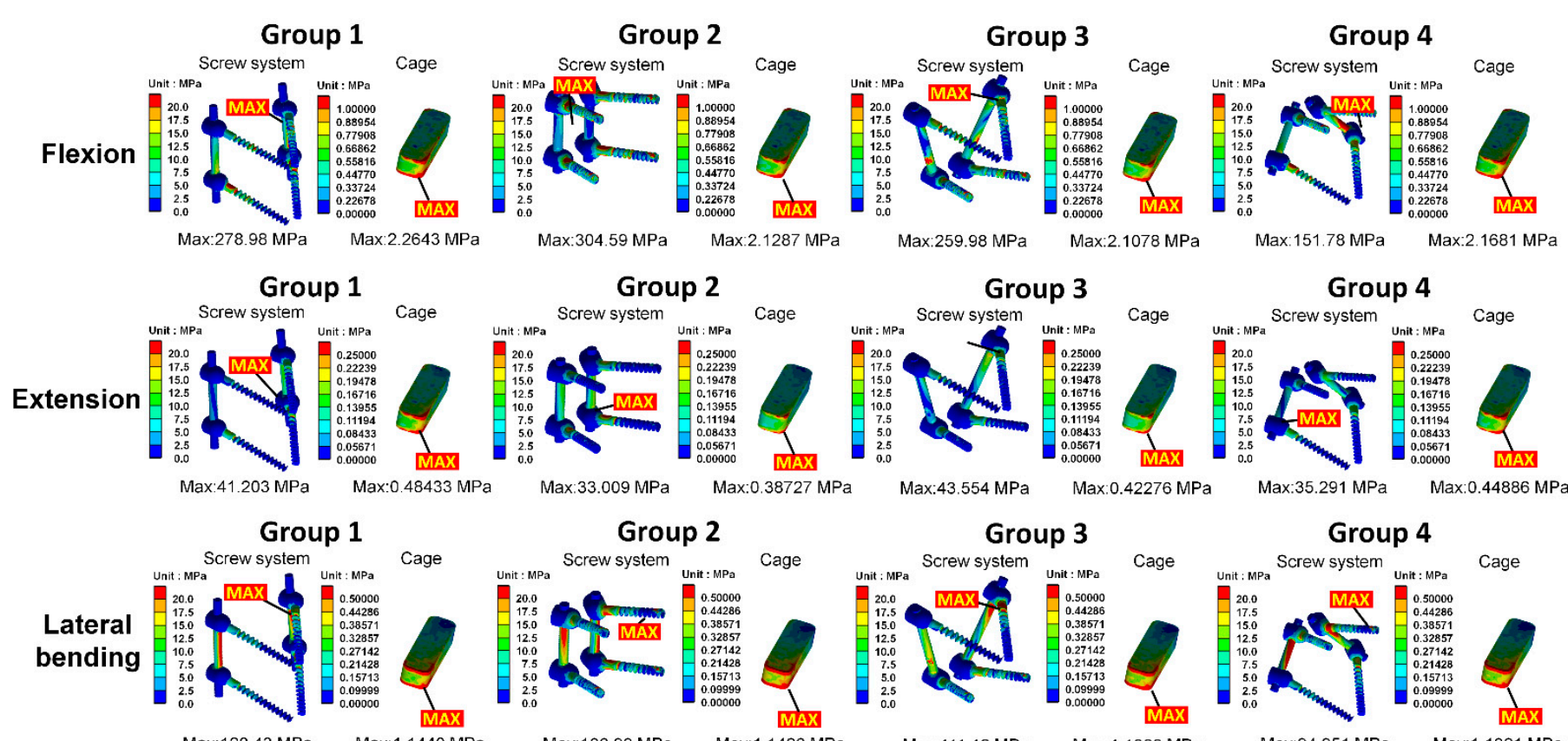

Group 2
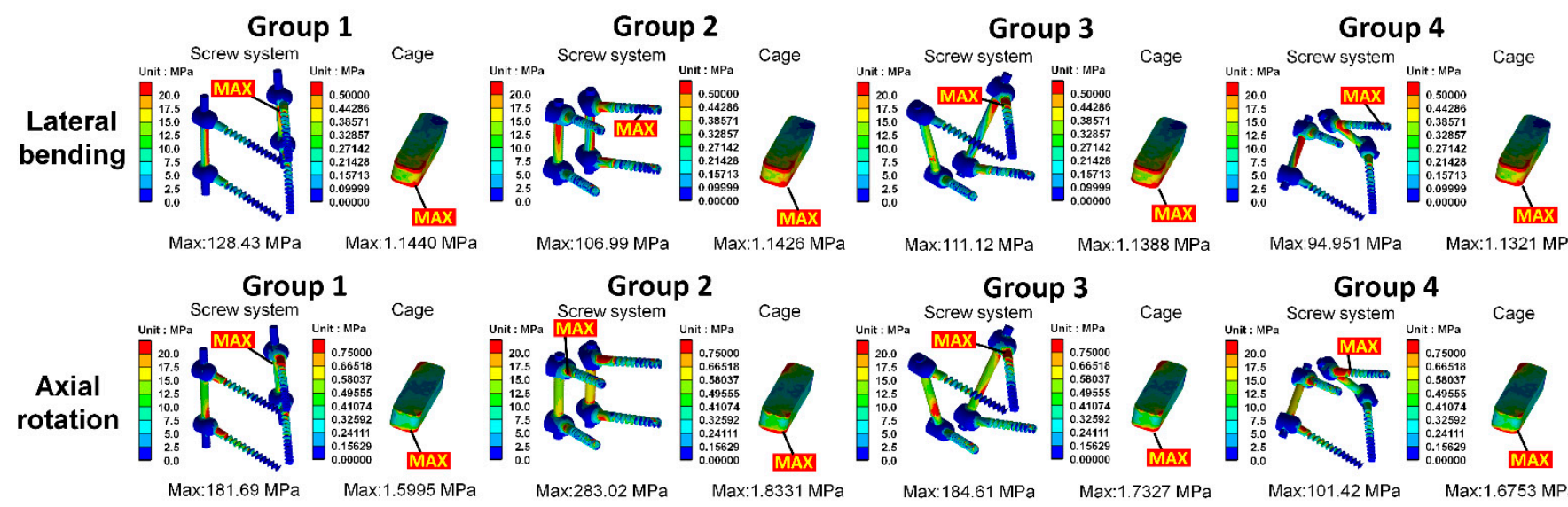

Figure 11. Distribution of von Mises stress on the screw system and cage.
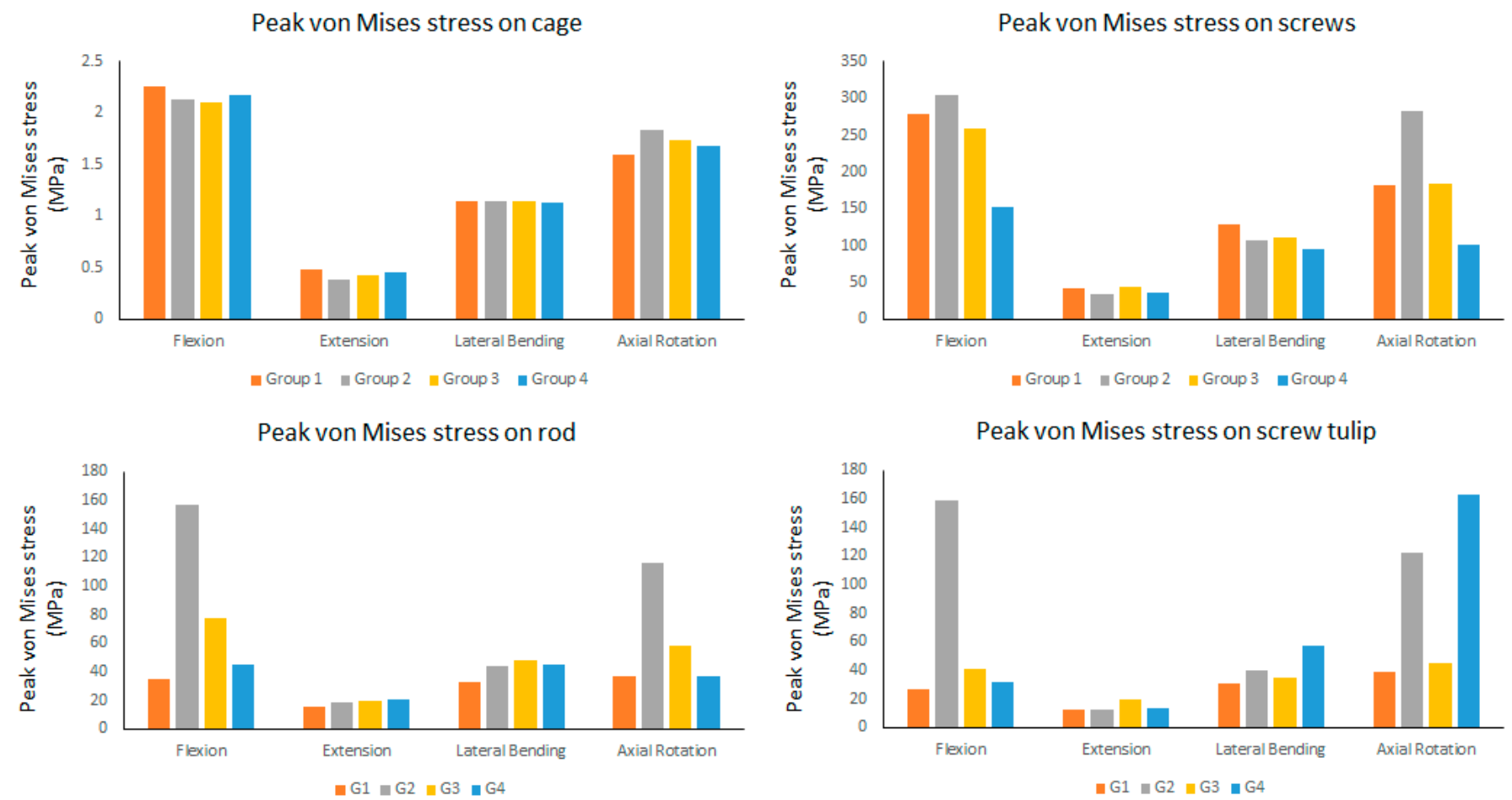

Figure 12. Peak von Mises stress on the cage and screw system. 
Table 2. The values of total deformation on the lumbar spine and the maximum von Mises stress values on the lumbar spine and screw system.

\begin{tabular}{|c|c|c|c|c|c|}
\hline Observation Indicators & Motion & Group 1 & Group 2 & Group 3 & Group 4 \\
\hline \multirow{4}{*}{$\begin{array}{l}\text { Total Deformation } \\
\qquad(\mathrm{mm})\end{array}$} & Flexion & 3.8823 & 3.6995 & 3.7367 & 3.8419 \\
\hline & Extension & 0.98531 & 0.93348 & 0.94502 & 0.96987 \\
\hline & Lateral Bending & 2.9165 & 2.8883 & 2.8767 & 2.9032 \\
\hline & Axial Rotation & 2.5345 & 2.4754 & 2.5014 & 2.5258 \\
\hline \multirow{4}{*}{$\begin{array}{c}\text { Maximum von Mises } \\
\text { stress in the lower } \\
\text { endplate of L2 } \\
(\mathrm{MPa})\end{array}$} & Flexion & 24.198 & 14.136 & 14.318 & 14.781 \\
\hline & Extension & 4.3587 & 2.3782 & 2.4403 & 2.618 \\
\hline & Lateral Bending & 11.249 & 7.1925 & 7.1488 & 7.2184 \\
\hline & Axial Rotation & 10.917 & 6.9309 & 7.0111 & 7.0879 \\
\hline \multirow{4}{*}{$\begin{array}{l}\text { Maximum von Mises } \\
\text { stress in the upper } \\
\text { endplate of L5 } \\
(\mathrm{MPa})\end{array}$} & Flexion & 2.8133 & 2.6856 & 2.724 & 2.7806 \\
\hline & Extension & 0.61285 & 0.6596 & 0.64281 & 0.61415 \\
\hline & Lateral Bending & 1.6028 & 1.5632 & 1.5589 & 1.5739 \\
\hline & Axial Rotation & 2.1384 & 2.0675 & 2.1007 & 2.1234 \\
\hline \multirow{4}{*}{$\begin{array}{c}\text { Maximum von Mises } \\
\text { stress in L2 of the } \\
\text { lumbar spine } \\
(\mathrm{MPa})\end{array}$} & Flexion & 51.748 & 49.002 & 49.646 & 51.296 \\
\hline & Extension & 24.529 & 24.524 & 24.534 & 24.524 \\
\hline & Lateral Bending & 30.916 & 30.726 & 30.525 & 30.816 \\
\hline & Axial Rotation & 27.205 & 26.735 & 27.06 & 27.373 \\
\hline \multirow{4}{*}{$\begin{array}{c}\text { Maximum von Mises } \\
\text { stress in L3 of the } \\
\text { lumbar spine } \\
(\mathrm{MPa})\end{array}$} & Flexion & 387.75 & 117.79 & 360.54 & 133.85 \\
\hline & Extension & 45.282 & 16.088 & 36.571 & 16.114 \\
\hline & Lateral Bending & 174.59 & 74.884 & 162.28 & 73.462 \\
\hline & Axial Rotation & 281.61 & 146.53 & 277.87 & 144.44 \\
\hline \multirow{4}{*}{$\begin{array}{c}\text { Maximum von Mises } \\
\text { stress in L4 of the } \\
\text { lumbar spine } \\
(\mathrm{MPa})\end{array}$} & Flexion & 31.918 & 137.22 & 141.65 & 174.75 \\
\hline & Extension & 6.7604 & 13.676 & 11.691 & 15.19 \\
\hline & Lateral Bending & 15.194 & 61.073 & 62.162 & 115.76 \\
\hline & Axial Rotation & 28.869 & 105.49 & 109.36 & 178.67 \\
\hline \multirow{4}{*}{$\begin{array}{c}\text { Maximum von Mises } \\
\text { stress in L5 of the } \\
\text { lumbar spine } \\
(\mathrm{MPa})\end{array}$} & Flexion & 22.667 & 22.032 & 22.156 & 22.514 \\
\hline & Extension & 18.48 & 18.371 & 18.4 & 18.434 \\
\hline & Lateral Bending & 31.521 & 31.463 & 31.172 & 31.024 \\
\hline & Axial Rotation & 26.875 & 26.069 & 26.597 & 26.826 \\
\hline \multirow{4}{*}{$\begin{array}{c}\text { Maximum von Mises } \\
\text { stress on cage } \\
(\mathrm{MPa})\end{array}$} & Flexion & 2.2643 & 2.1287 & 2.1078 & 2.1681 \\
\hline & Extension & 0.48433 & 0.38727 & 0.42276 & 0.44886 \\
\hline & Lateral Bending & 1.144 & 1.1426 & 1.1388 & 1.1321 \\
\hline & Axial Rotation & 1.5995 & 1.8331 & 1.7327 & 1.6753 \\
\hline \multirow{4}{*}{$\begin{array}{c}\text { Maximum von Mises } \\
\text { stress on screw } \\
(\mathrm{MPa})\end{array}$} & Flexion & 278.98 & 304.59 & 259.98 & 151.78 \\
\hline & Extension & 41.203 & 33.009 & 43.554 & 35.291 \\
\hline & Lateral Bending & 128.43 & 106.99 & 111.12 & 94.951 \\
\hline & Axial Rotation & 181.69 & 283.02 & 184.61 & 101.42 \\
\hline \multirow{4}{*}{$\begin{array}{l}\text { Maximum von Mises } \\
\text { stress on rod } \\
(\mathrm{MPa})\end{array}$} & Flexion & 35.291 & 156.740 & 77.120 & 44.687 \\
\hline & Extension & 15.342 & 18.377 & 19.979 & 20.651 \\
\hline & Lateral Bending & 32.976 & 44.394 & 47.588 & 45.462 \\
\hline & Axial Rotation & 36.397 & 115.720 & 58.548 & 37.100 \\
\hline \multirow{4}{*}{$\begin{array}{l}\text { Maximum von Mises } \\
\text { stress on screw tulip } \\
(\mathrm{MPa})\end{array}$} & Flexion & 26.592 & 158.63 & 40.654 & 31.28 \\
\hline & Extension & 12.445 & 12.318 & 19.267 & 13.312 \\
\hline & Lateral Bending & 30.308 & 40.019 & 34.393 & 57.484 \\
\hline & Axial Rotation & 39.04 & 122.25 & 44.963 & 162.73 \\
\hline
\end{tabular}

\section{Discussion}

In this study, the biomechanical effects of the traditional pedicle screw and CBT screw implant on the lumbar spine were successfully investigated using finite element analysis. Although previous research pointed out that the CBT system can be used in spine revision surgery with reduced blood loss and fixation ability and reduced surgical failure rate $[6,7]$, there is no biomechanical basis for implantation of the traditional pedicle screw system and the CBT system in the lumbar spine. The results of this study may provide a basis for 
clinical spinal surgeons to consider the biomechanics of cortical trajectory systems during retrofit surgery.

By observing the deformation of the lumbar spine, the results showed that there was no significant difference between groups. There was no significant difference in overall spinal stability between the use of a traditional pedicle screw system, CBT system, or both. However, the CBT system implantation was slightly more stable than the traditional pedicle screw system. In addition, lumbar spine stress distribution was observed after implantation of the traditional pedicle screw system or CBT system. The results show that there are obvious differences in stress distribution under four different load conditions. There was no significant difference in stress distribution in the lumbar spine with different implants. The CBT system was used clinically with a finer screw diameter (approximately $4.5 \mathrm{~mm}$ in diameter) than the traditional pedicle screw system (approximately $6.5 \mathrm{~mm}$ in diameter). The CBT system and traditional pedicle screw system showed similar stability in mechanical studies $[15,32]$. The results of this study may be inconsistent with those of previous studies [16], mainly because the cage for transforaminal lumbar interbody fusion is implanted in the model of this study. Therefore, cage implantation may make the whole spinal structure more stable. There were also clinical studies involving a traditional pedicle screw system and CBT system using cage implantation [33]. The CBT system was used to achieve stability comparable to that of the traditional pedicle screw system.

In addition, the stress of the lumbar L3 and L4 showed low stress under four different loading conditions. This can be explained by the stress shielding effect (When the difference in elastic modulus between the screw system and the bone is large, the stress shielding effect will be more obvious. The force is transmitted mainly by the screw system, so the stress on the bone is reduced.). With the high rigidity of the implanted screw system, higher stresses occur in the adjacent vertebrae (the lumbar L2 and L5).

Peak von Mises stress on the endplate was observed and higher stress was found in the endplate implanted on the upper side of the traditional pedicle screw system. The CBT system is used in the lower endplate of L2 with lower peak stress. The CBT system may reduce the stress on the endplate (Group 3 and Group 4 also exhibit less stress on the endplate than Group 1). However, more clinical evidence is needed to confirm whether the CBT system can reduce the injury of the adjacent lumbar segment.

The CBT is mainly based on screw implantation of the cortical bone to achieve stability. Therefore, observing the upper vertebral body of the implant system in this study, peak von Mises stress in the lumbar L3 could be observed with lower stress on the lumbar vertebral body implanted in the cortical trajectory. The screw of the CBT system is fixed to the cortical bone, and Young's modulus in cortical bone is bigger than Young's modulus in cancellous bone. Thus, the lumbar L3 used the CBT system with minor deformation in the spine lumbar vertebral body. According to Hook's law, stress is proportional to strain, so there is less stress in the lumbar vertebrae implanted with a CBT screw. In addition, observing the lower vertebral body of the implant system in this study, the screws of CBT screws are inserted from the bottom up and from the inside out. Therefore, the vertebra of the spine is only partially supported by screws. As a result, the vertebral body (the lumbar L4) deforms greatly and produces high stress. In Group 4, greater deformation occurred in the lumbar L4 because of the placement of screws in the lumbar L4 with cancellous bone and the use of CBT in the lumbar L3. Therefore, Group 4 has higher stress in the lower vertebral body (the lumbar L4).

In addition, distribution of von Mises stress on the screw system and cage was observed. High stress of the screw system mainly occurs near the joint of the screw and screw tulip. Therefore, the clinical spinal surgeon must tighten the screws when fixing the screw system. This may cause loosening of the screw system during the movement of the patient. The high stress of the cage mainly occurs at the cage edge. Therefore, arc design can be used to avoid high stress in cage design. In addition, titanium alloy was used for the cage, traditional pedicle screw system, and CBT system in this study. The yield stress of titanium alloy is about $1100 \mathrm{MPa}$ [34]. The stress value of the cage and screw system 
observed in this study is much lower than $1100 \mathrm{MPa}$, so the cage and screw system would not cause permanent deformation under the load in this study.

In addition, the area enclosed by four screw tulips in each group was observed from the posterior of the spine (Figure 13). The CBT is used in Group 2, which is approximately half of the area surrounded by the traditional pedicle screw system. The area of group 4 was about half that of the traditional pedicle screw system. However, the area of group 3 was similar to that of the traditional pedicle screw system. Therefore, if a clinical surgeon wants to perform spinal revision surgery, the patient was originally treated with a traditional pedicle screw system. Clinical spinal surgeons may consider using CBT for revision surgery. This may allow patients to have smaller wounds [8,35]. In addition to the advantage of a smaller wound, the clinician has a smaller area of muscle to open when using CBT screws. According to previous research results, it is pointed out that dysfunction of these muscles may be associated with increased pain [36,37]. Therefore, postoperative pain is reduced, and minimally invasive surgery could be achieved.
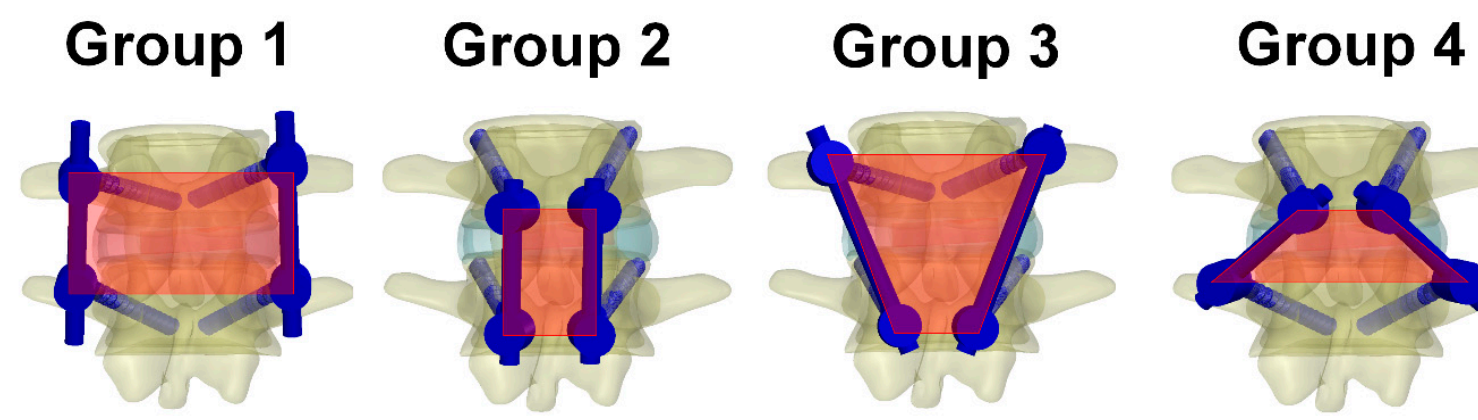

\section{Red area ratio

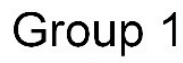

1
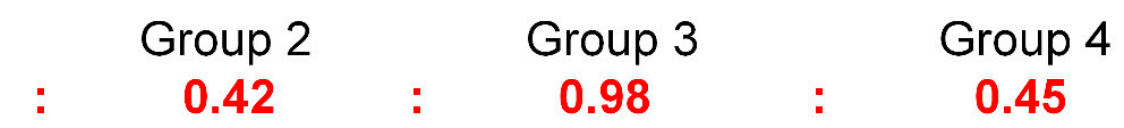

Figure 13. The area surrounded by four screw tulips in each group was viewed from the posterior of the spine.

There are some limitations to this study. The material properties used in this study should be set as anisotropic on bone or hyperelastic material on the intervertebral disc by previous research [22]. However, it is not easy to solve using nonlinear analysis in finite element analysis. In addition, the intervertebral disc structure established in this study is quite complex (the intervertebral disc model of this study contains 5 nucleus pulposus, 4204 annulus fibrosis, and 35 annulus ground substances). In order to avoid the use of nonlinear material properties and thus lead to the influence of the main topic to be discussed in this study, the properties of the materials in this study were mainly selected by homogeneous, isotropic, and linearly elastic materials. In addition, the screw system used in the simulation model of this study uses screws with a diameter of $5.5 \mathrm{~mm}$, so the screw size is not consistent with the actual clinical use. The purpose of the mechanical evaluation was to compare the contrast between the traditional pedicle screw system and the CBT system and to avoid the influence of the screw diameter. In addition, the shape of the cage was also represented by a simple square shape, mainly to avoid the high stress caused by the serrated cage, which made the analysis results difficult in this study. After such simplification, this study may have some differences from the actual situation. However, it will not seriously affect the trend of research results. Such simplification can make the topics concerned by this research have more obvious trends. In addition, only two lumbar vertebrae were used for simulation evaluation in this study. Clinical spinal revision surgery usually involves the operation of more than two lumbar vertebrae. Therefore, after the evaluation of this study, more biomechanical evaluations of vertebral fixation can be performed in the future.

This study evaluated the effects of the CBT screw and traditional pedicle screw implantation on the lumbar spine by finite element analysis. Although the results analyzed 
in this study may be slightly different from the actual situation. However, the results of this study provide a biomechanical reference for spinal surgeons when selecting screw systems.

\section{Conclusions}

This study analyzed the effects of the traditional pedicle screw system and CBT system implantation on the lumbar spine. The results showed that there was no significant difference in stability between the traditional pedicle screw system and CBT system after implantation with the cage. In addition, the CBT system may reduce the stress on the endplate. Different movements performed by the patient may have a significant mechanical impact on the spine and implant system. When performing spinal revision surgery, clinical spinal surgeons may also consider using the CBT system for spinal revision surgery, which may contribute to smaller wounds.

Author Contributions: Conceptualization, K.-H.C. and C.-H.L.; methodology, K.-C.S.; data curation, K.-C.S.; writing-original draft preparation, K.-C.S. and C.-C.P.; writing-review and editing, K.-C.S. and C.-H.L. All authors have read and agreed to the published version of the manuscript.

Funding: This research received no external funding.

Institutional Review Board Statement: Not applicable.

Informed Consent Statement: Not applicable.

Data Availability Statement: Not applicable.

Acknowledgments: We would like to thank Taichung Veterans General Hospital (TCVGH-1107315C and TCVGH-1105101C) in Taiwan and the 3D Printing Research and Development Group of Taichung Veterans General Hospital for building the simulation computer model of this study.

Conflicts of Interest: The authors declare no conflict of interest.

\section{References}

1. Ponnusamy, K.E.; Iyer, S.; Gupta, G.; Khanna, A.J. Instrumentation of the osteoporotic spine: Biomechanical and clinical considerations. Spine J. 2011, 11, 54-63. [CrossRef] [PubMed]

2. Park, P.; Garton, H.J.; Gala, V.C.; Hoff, J.T.; McGillicuddy, J.E. Adjacent Segment Disease after Lumbar or Lumbosacral Fusion: Review of the Literature. Spine 2004, 29, 1938-1944. [CrossRef] [PubMed]

3. Martin, B.I.; Mirza, S.K.; Comstock, B.A.; Gray, D.T.; Kreuter, W.; Deyo, R.A. Are Lumbar Spine Reoperation Rates Falling with Greater Use of Fusion Surgery and New Surgical Technology? Spine 2007, 32, 2119-2126. [CrossRef] [PubMed]

4. Tobert, D.G.; Antoci, V.; Patel, S.; Saadat, E.; Bono, C.M. Adjacent Segment Disease in the Cervical and Lumbar Spine. Clin. Spine Surg. 2017, 30, 94-101. [CrossRef]

5. Bederman, S.S.; Le, V.H.; Pahlavan, S. An Approach to Lumbar Revision Spine Surgery in Adults. J. Am. Acad. Orthop. Surg. 2016, 24, 433-442. [CrossRef]

6. Dabbous, B.; Brown, D.; Tsitlakidis, A.; Arzoglou, V. Clinical outcomes during the learning curve of MIDline Lumbar Fusion (MIDLF®) using the cortical bone trajectory. Acta Neurochir. 2016, 158, 1413-1420. [CrossRef]

7. Delgado-Fernandez, J.; García-Pallero, M.Á.; Blasco, G.; Pulido-Rivas, P.; Rafael, G.S. Review of Cortical Bone Trajectory: Evidence of a New Technique. Asian Spine J. 2017, 11, 817-831. [CrossRef]

8. Santoni, B.; Hynes, R.; McGilvray, K.; Rodriguez-Canessa, G.; Lyons, A.; Henson, M.; Womack, W.; Puttlitz, C. Cortical bone trajectory for lumbar pedicle screws. Spine J. 2009, 9, 366-373. [CrossRef]

9. Matsukawa, K.; Yato, Y.; Kato, T.; Imabayashi, H.; Asazuma, T.; Nemoto, K. Cortical bone trajectory for lumbosacral fixation: Penetrating S-1 endplate screw technique. J. Neurosurg. Spine 2014, 21, 203-209. [CrossRef]

10. Chen, C.-H.; Huang, H.-M.; Chen, D.-C.; Wu, C.-Y.; Lee, H.-C.; Cho, D.-Y. Cortical bone trajectory screws fixation in lumbar adjacent segment disease: A technique note with case series. J. Clin. Neurosci. 2018, 48, 224-228. [CrossRef]

11. Tortolani, P.J.; Stroh, D.A. Cortical Bone Trajectory Technique for Posterior Spinal Instrumentation. J. Am. Acad. Orthop. Surg. 2016, 24, 755-761. [CrossRef] [PubMed]

12. Ueno, M.; Imura, T.; Inoue, G.; Takaso, M. Posterior corrective fusion using a double-trajectory technique (cortical bone trajectory combined with traditional trajectory) for degenerative lumbar scoliosis with osteoporosis. J. Neurosurg. Spine 2013, 19, 600-607. [CrossRef] [PubMed]

13. Wang, J.; He, X.; Sun, T. Comparative clinical efficacy and safety of cortical bone trajectory screw fixation and traditional pedicle screw fixation in posterior lumbar fusion: A systematic review and meta-analysis. Eur. Spine J. 2019, 28, 1678-1689. [CrossRef] [PubMed] 
14. Matsukawa, K.; Yato, Y.; Imabayashi, H.; Hosogane, N.; Asazuma, T.; Nemoto, K. Biomechanical Evaluation of Cross Trajectory Technique for Pedicle Screw Insertion: Combined Use of Traditional Trajectory and Cortical Bone Trajectory. Orthop. Surg. 2015, 7, 317-323. [CrossRef]

15. Matsukawa, K.; Yato, Y.; Imabayashi, H.; Hosogane, N.; Abe, Y.; Asazuma, T.; Chiba, K. Biomechanical evaluation of fixation strength among different sizes of pedicle screws using the cortical bone trajectory: What is the ideal screw size for optimal fixation? Acta Neurochir. 2016, 158, 465-471. [CrossRef] [PubMed]

16. Liu, C.-W.; Wang, L.-L.; Xu, Y.-K.; Chen, C.-M.; Wang, J.-C.; Tsai, W.-T.; Lin, S.-C. Traditional and cortical trajectory screws of static and dynamic lumbar fixation-a finite element study. BMC Musculoskelet. Disord. 2020, 21, 463. [CrossRef] [PubMed]

17. Zhang, L.; Li, H.-M.; Zhang, R.; Zhang, H.; Shen, C.-L. Biomechanical Changes of Adjacent and Fixed Segments through Cortical Bone Trajectory Screw Fixation versus Traditional Trajectory Screw Fixation in the Lumbar Spine: A Finite Element Analysis. World Neurosurg. 2021, 151, e447-e456. [CrossRef]

18. Matsukawa, K.; Yato, Y.; Imabayashi, H.; Hosogane, N.; Asazuma, T.; Chiba, K. Biomechanical evaluation of lumbar pedicle screws in spondylolytic vertebrae: Comparison of fixation strength between the traditional trajectory and a cortical bone trajectory. J. Neurosurg. Spine 2016, 24, 910-915. [CrossRef]

19. Wang, T.; Wu, B.; Duan, R.; Yuan, Y.; Qu, M.; Zhang, S.; Huang, W.; Liu, T.; Yu, X. Treatment of Thoracolumbar Fractures Through Different Short Segment Pedicle Screw Fixation Techniques: A Finite Element Analysis. Orthop. Surg. 2020, 12, 601-608. [CrossRef]

20. Choi, K.-C.; Ryu, K.-S.; Lee, S.-H.; Kim, Y.H.; Lee, S.J.; Park, C.-K. Biomechanical comparison of anterior lumbar interbody fusion: Stand-alone interbody cage versus interbody cage with pedicle screw fixation-A finite element analysis. BMC Musculoskelet. Disord. 2013, 14, 220. [CrossRef]

21. Erbulut, D.; Zafarparandeh, I.; Hassan, C.R.; Lazoglu, I.; Ozer, A.F. Determination of the biomechanical effect of an interspinous process device on implanted and adjacent lumbar spinal segments using a hybrid testing protocol: A finite-element study. J. Neurosurg. Spine 2015, 23, 200-208. [CrossRef]

22. Schmidt, H.; Heuer, F.; Simon, U.; Kettler, A.; Rohlmann, A.; Claes, L.; Wilke, H.-J. Application of a new calibration method for a three-dimensional finite element model of a human lumbar annulus fibrosus. Clin. Biomech. 2006, 21, 337-344. [CrossRef] [PubMed]

23. Lo, H.-J.; Chen, C.-S.; Chen, H.-M.; Yang, S.-W. Application of an interspinous process device after minimally invasive lumbar decompression could lead to stress redistribution at the pars interarticularis: A finite element analysis. BMC Musculoskelet. Disord. 2019, 20, 213. [CrossRef] [PubMed]

24. Charles, Y.P.; Lima, L.V.P.C.; Persohn, S.; Rouch, P.; Steib, J.-P.; Skalli, W. Influence of an auxiliary facet system on intervertebral discs and adjacent facet joints. Spine J. 2013, 13, 1293-1300. [CrossRef] [PubMed]

25. Denozière, G.; Ku, D.N. Biomechanical comparison between fusion of two vertebrae and implantation of an artificial intervertebral disc. J. Biomech. 2006, 39, 766-775. [CrossRef] [PubMed]

26. Kim, H.-J.; Kang, K.-T.; Son, J.; Lee, C.-K.; Chang, B.-S.; Yeom, J.S. The influence of facet joint orientation and tropism on the stress at the adjacent segment after lumbar fusion surgery: A biomechanical analysis. Spine J. 2015, 15, 1841-1847. [CrossRef] [PubMed]

27. Wu, Y.; Wang, Y.; Wu, J.; Guan, J.; Mao, N.; Lu, C.; Lv, R.; Ding, M.; Shi, Z.; Cai, B. Study of Double-level Degeneration of Lower Lumbar Spines by Finite Element Model. World Neurosurg. 2016, 86, 294-299. [CrossRef]

28. Kim, Y. Finite element analysis of anterior lumbar interbody fusion: Threaded cylindrical cage and pedicle screw fixation. Spine 2007, 32, 2558-2568. [CrossRef]

29. Ambati, D.V.; Wright, E.K., Jr.; Lehman, R.A., Jr.; Kang, D.G.; Wagner, S.C.; Dmitriev, A.E. Bilateral pedicle screw fixation provides superior biomechanical stability in transforaminal lumbar interbody fusion: A finite element study. Spine J. 2015, 15, 1812-1822 [CrossRef]

30. Zhong, Z.-C.; Wei, S.-H.; Wang, J.-P.; Feng, C.-K.; Chen, C.-S.; Yu, C.-H. Finite element analysis of the lumbar spine with a new cage using a topology optimization method. Med. Eng. Phys. 2006, 28, 90-98. [CrossRef]

31. Lin, C.-L.; Chang, Y.-H.; Liu, P.-R. Multi-factorial analysis of a cusp-replacing adhesive premolar restoration: A finite element study. J. Dent. 2008, 36, 194-203. [CrossRef] [PubMed]

32. Perez-Orribo, L.; Kalb, S.; Reyes, P.M.; Chang, S.W.; Crawford, N.R. Biomechanics of Lumbar Cortical Screw-Rod Fixation Versus Pedicle Screw-Rod Fixation with and Without Interbody Support. Spine 2013, 38, 635-641. [CrossRef] [PubMed]

33. Kasukawa, Y.; Miyakoshi, N.; Hongo, M.; Ishikawa, Y.; Kudo, D.; Shimada, Y. Short-Term Results of Transforaminal Lumbar Interbody Fusion Using Pedicle Screw with Cortical Bone Trajectory Compared with Conventional Trajectory. Asian Spine J. 2015, 9, 440-448. [CrossRef] [PubMed]

34. Enderle, J.; Bronzino, J. Introduction to Biomedical Engineering; Academic Press: Boston, MA, USA, 2012.

35. Keorochana, G.; Pairuchvej, S.; Trathitephun, W.; Arirachakaran, A.; Predeeprompan, P.; Kongtharvonskul, J. Comparative Outcomes of Cortical Screw Trajectory Fixation and Pedicle Screw Fixation in Lumbar Spinal Fusion: Systematic Review and Meta-analysis. World Neurosurg. 2017, 102, 340-349. [CrossRef] [PubMed] 
36. Freeman, M.D.; Woodham, M.A.; Woodham, A.W. The Role of the Lumbar Multifidus in Chronic Low Back Pain: A Review. PMER 2010, 2, 142-146. [CrossRef]

37. Bresnahan, L.E.; Smith, J.S.; Ogden, A.T.; Quinn, S.; Cybulski, G.R.; Simonian, N.; Natarajan, R.N.; Fessler, R.D.; Fessler, R.G. Assessment of paraspinal muscle cross-sectional area after lumbar decompression: Minimally invasive versus open approaches. Clin. Spine Surg. 2017, 30, E162-E168. [CrossRef] 